\title{
Magnesium supplementation during cardiopulmonary bypass to prevent junctional ectopic tachycardia after pediatric cardiac surgery: A randomized controlled study
}

\author{
Ana M. Manrique, MD, ${ }^{\text {a }}$ Margarita Arroyo, MD, ${ }^{\mathrm{a}}$ Yan Lin, $\mathrm{PhD},{ }^{\mathrm{b}}$ Samar R. El Khoudary, $\mathrm{PhD}, \mathrm{MPH},{ }^{\mathrm{c}}$ \\ Erin Colvin, RN, BSN, CCRN, ${ }^{\mathrm{a}}$ Steven Lichtenstein, MD, ${ }^{\mathrm{d}}$ Constantinos Chrysostomou, MD,${ }^{\mathrm{f}}$ \\ Richard Orr, MD, ${ }^{\mathrm{f}}$ Edmund Jooste, MD, ${ }^{\mathrm{d}}$ Peter Davis, MD, ${ }^{\mathrm{d}}$ Peter Wearden, MD, PhD, ${ }^{\mathrm{e}}$ \\ Victor Morell, $\mathrm{MD},{ }^{\mathrm{e}}$ and Ricardo Munoz, $\mathrm{MD}^{\mathrm{f}}$
}

\begin{abstract}
Objectives: We analyzed the role of magnesium sulfate $\left(\mathrm{MgSO}_{4}\right)$ supplementation during cardiopulmonary bypass in pediatric patients undergoing cardiac surgery, assessing the incidence of hypomagnesemia and the incidence of junctional ectopic tachycardia.
\end{abstract}

\begin{abstract}
Methods: We performed a randomized, double-blind, controlled trial in 99 children. $\mathrm{MgSO}_{4}$ or placebo was administered during the rewarming phase of cardiopulmonary bypass: group 1, placebo group (29 patients); group 2, $25 \mathrm{mg} / \mathrm{kg}$ of $\mathrm{MgSO}_{4}$ (30 patients); and group 3, $50 \mathrm{mg} / \mathrm{kg}$ of $\mathrm{MgSO}_{4}$ (40 patients).
\end{abstract}

\begin{abstract}
Results: At the time of admission to the cardiac intensive care unit, groups receiving $\mathrm{MgSO}_{4}$ had significantly greater levels of ionized magnesium (group 1, $0.51 \pm 0.07$; group 2, $0.57 \pm 0.09$; group 3, $0.59 \pm 0.09$ ). Hypomagnesemia before bypass was common $(75 \%-86.2 \%)$ and not significantly different among the groups. The proportion of hypomagnesemia decreased significantly at admission to the cardiac intensive care unit in groups receiving $\mathrm{MgSO}_{4}$ (group 1,77.8\%; group 2, 63\%; group 3, 47.4\%). Patients receiving placebo (group 1) had a significantly greater occurrence of junctional ectopic tachycardia than groups receiving $\mathrm{MgSO}_{4}$ (group $1, \mathrm{n}$ $=5[17.9 \%]$; group $2, \mathrm{n}=2[6.7 \%]$; group $3, \mathrm{n}=0[0 \%])$. Age $(<1$ month), Aristotle score $(>4)$, and history of cardiac failure were associated with junctional ectopic tachycardia. None of the patients with those characteristics in group 3 had junctional ectopic tachycardia. No association was found between study groups and the Pediatric Risk of Mortality score or length of stay in the cardiac intensive care unit.
\end{abstract}

Conclusions: Supplementation with $\mathrm{MgSO}_{4}$ during cardiopulmonary bypass seems to reduce the incidence of hypomagnesemia and junctional ectopic tachycardia at admission to the cardiac intensive care unit. This effect seems to be dose related. (J Thorac Cardiovasc Surg 2010;139:162-9)

Supplemental material is available online.

Postoperative arrhythmias are an important cause of morbidity and mortality after cardiac surgery for congenital heart disease. In the early postoperative period, patients with

From the Department of Pediatrics, Heart Center, Children's Hospital of Pittsburgh, ${ }^{\mathrm{a}}$ the Department of Medicine, Department of Biostatistics, University of Pittsburgh, ${ }^{\text {b }}$ the Department of Medicine, Department of Epidemiology, University of Pittsburgh, ${ }^{\mathrm{c}}$ the Department of Anesthesiology, Children's Hospital of Pittsburgh, ${ }^{\mathrm{d}}$ the Department of Cardiothoracic Surgery Children's Hospital of Pittsburgh, ${ }^{\mathrm{e}}$ and the Department of Critical Care Medicine, Division of Cardiac Intensive Care, Children's Hospital of Pittsburgh, ${ }^{\mathrm{f}}$ University of Pittsburgh, Pittsburgh, Pa.

Disclosures: Partially supported by funds from the Nova Biomedical Corporation (Waltham, Mass).

Presented and awarded at the European Symposium of the Pediatric Cardiac Intensive Care Society (March 2008) (Young Investigator Award).

Received for publication Sept 30, 2008; revisions received May 27, 2009; accepted for publication July 23, 2009; available ahead of print Oct 12, 2009.

Address for reprints: Ricardo Munoz, MD, FAAP, FCCM, Chief, Cardiac Intensive Care Division; Director, Cardiac Recovery Program, Children's Hospital of Pittsburgh of UPMC Heart Center, 3705 Fifth Ave, Pittsburgh, PA 15213 (E-mail: munorx@ccm.upmc.edu).

0022-5223/\$36.00

Copyright (c) 2010 by The American Association for Thoracic Surgery doi:10.1016/j.jtcvs.2009.07.064 congenital heart disease are especially vulnerable to rhythm disturbances. In pediatric cardiac surgery, there is little information regarding the incidence, risk factors, management, and prophylaxis for early postoperative arrhythmias. A recent report by Roos-Hesselink and Karamermer ${ }^{1}$ noted an incidence between $15 \%$ and $17.7 \%$. Postoperative junctional ectopic tachycardia (JET) remains one of the most common arrhythmias $(8 \%-20 \%)$ after pediatric cardiac surgery. JET is associated with hemodynamic instability, longer mechanical ventilation time, and longer stays in the cardiac intensive care unit (CICU). ${ }^{2}$ Although the etiology of JET is multifactorial, some studies have associated the presence of JET with hypomagnesemia during cardiopulmonary bypass $(\mathrm{CPB}){ }^{3}$

Magnesium is an important regulator of multiple cardiovascular processes, including myocardial conduction and contractility, transmembrane calcium flux, potassium transport, vascular smooth muscle tone, coronary reactivity, and nitric oxide synthesis. One percent of total magnesium is distributed in the extracellular fluid, where $55 \%$ of it is in the physiologic active form: ionized magnesium (iMg). Measurement of iMg is currently available and its assessment is reflective of the intracellular magnesium status. ${ }^{4,5}$ 


\section{Abbreviations and Acronyms \\ CICU = cardiac intensive care unit \\ $\mathrm{CPB}=$ cardiopulmonary bypass \\ $\mathrm{iMg}=$ ionized magnesium \\ JET = junctional ectopic tachycardia \\ $\mathrm{MgSO}_{4}=$ magnesium sulfate \\ PRISM $=$ Pediatric Risk of Mortality}

Inasmuch as magnesium is an essential cofactor for the maintenance of myocardial transmembrane potential, magnesium deficiency decreases the threshold for arrhythmias. ${ }^{6}$ In adults having cardiac surgery, hypomagnesemia has been associated with the presence of arrhythmias, especially postoperative atrial fibrillation. ${ }^{7-10}$ Furthermore, in adults the administration of magnesium sulfate $\left(\mathrm{MgSO}_{4}\right)$ during cardiac surgery reduces the occurrence of postoperative atrial fibrillation. ${ }^{11}$ In pediatric patients undergoing cardiac surgery with $\mathrm{CPB}$, hypomagnesemia is common $(34 \%)$ and is associated with longer CICU stay, higher Pediatric Risk of Mortality (PRISM) score, and longer mechanical ventilation time. ${ }^{12}$ Alhough magnesium supplementation during CPB reduces the incidence of arrhythmias in adults, the benefits of magnesium administration in pediatric cardiac patients have not been demonstrated nor have dosage guidelines been established.

The aim of this study was to determine the incidence of hypomagnesemia in pediatric patients undergoing cardiac surgery who require $\mathrm{CPB}$ and to evaluate the prophylactic administration of magnesium on the occurrence of postoperative arrhythmias. In addition, we study the influence of magnesium supplementation on the length of CICU stay and PRISM score.

\section{METHODS}

\section{Study Population and Design}

Between February 2005 and August 2006, we performed a randomized, double-blind, placebo-controlled trial in pediatric cardiac surgery patients requiring CPB. The study was approved by the Institutional Review Board of the University of Pittsburgh, and written informed consent was obtained from the parents of all the participants. Patients between birth and 17 years of age scheduled for elective cardiac surgery were eligible. Those with any medical disorder that required magnesium supplementation, such as malnutrition, sepsis, pancreatitis, or other conditions, were excluded. Neonates whose mothers received $\mathrm{MgSO}_{4}$ before or during the delivery, as well as patients who underwent emergency operations, were also excluded from the study. After informed written consent had been obtained from a parent, each patient was randomly assigned to one of the following groups: group 1, receiving normal saline (placebo), group 2, receiving $25 \mathrm{mg} / \mathrm{kg}$ of $\mathrm{MgSO}_{4}$, and group 3, receiving $50 \mathrm{mg} / \mathrm{kg}$ of $\mathrm{MgSO}_{4}$. Maximum total dose of $\mathrm{MgSO}_{4}$ did not exceed $2 \mathrm{~g}$. The study medication was prepared by the hospital pharmacy and was administered in a 5-mL syringe. All subjects received a single bolus of either placebo or drug into the $\mathrm{CPB}$ circuit at the initiation of the rewarming period. $\mathrm{MgSO}_{4}(500 \mathrm{mg} / \mathrm{mL} ; 4 \mathrm{mEq} / \mathrm{mL})$ was produced by SALF SpA (Cenate Sotto, Bergamo, Italy). Anesthesia was induced with sevoflurane and maintained with isoflurane, fentanyl, midazolam, and rocuronium. The composition of the bypass circuit and perfusion protocols were performed according to established institutional practices. The circuits were primed with a Plasma-Lyte solution (Baxter, Deerfield, Ill) and reconstituted blood was used as necessary to achieve a patient hematocrit level greater than $25 \%$. Heparin $(350 \mathrm{mg} / \mathrm{kg})$ was given to maintain activated coagulation time greater than 300 seconds. A custom-made cold blood cardioplegic solution was made according to previous protocols with $3 \mathrm{mEq} / \mathrm{L}$ of $\mathrm{MgSO}_{4}$. All patients received methylprednisolone at $30 \mathrm{mg} / \mathrm{kg}$ in the prime of the CPB circuit. Conventional hemofiltration was performed during $\mathrm{CPB}$. Ultrafiltration was used at the end of $\mathrm{CPB}$ in all patients less than $10 \mathrm{~kg}$, removing $60 \mathrm{~mL}$ of fluid per every kilogram of weight. A pH-stat acid-base management strategy was used when deep hypothermic circulatory arrest was performed. Potassium chloride and calcium chloride were given to maintain normal serum concentrations during surgery. At the end of the operation, all patients received $1 \mathrm{mg} / \mathrm{kg}$ furosemide (maximum dose $20 \mathrm{mg}$ ). Protamine was given to reverse heparin (1.3:1). No antiarrhythmics were administered during the operation to any patient. At the end of the surgical procedure, all the patients were transferred to the CICU. If clinically appropriate, patients were weaned from the ventilator and extubated. Weaning from inotropic infusions in the CICU was guided by standard hemodynamic criteria. Postoperative JET was managed by the CICU intensivist. The general approach to JET consisted of cooling the patient to $34^{\circ} \mathrm{C}$ and administering amiodarone $(5 \mathrm{mg} / \mathrm{kg}$ over 30 minutes, followed by an infusion of $15 \mathrm{mg} / \mathrm{kg}$ per day).

\section{Study Measurements}

The iMg level was measured at 4 time points: (1) baseline (time 1), before CPB; (2) approximately 10 minutes after initiation of the CPB (time 2); (3) approximately 10 minutes after study solution administration during the rewarming period of CPB (time 3); and (4) at the admission to the CICU (time 4). Arterial blood ( $1 \mathrm{~mL}$ ) was collected into a heparinized syringe (25 USP of dry heparin per milliliter) and $\mathrm{iMg}$ was immediately analyzed with the Ultra C analyzer (Nova Biomedical, Waltham, Mass). All the measurements were performed by the same operator and using the same machine. Quality controls were performed each day of the study. The presence of hypomagnesemia was based on iMg reference levels adjusted for age. ${ }^{12}$ A 12-lead electrocardiogram was performed on arrival in the CICU and an atrial electrocardiogram, using the temporary epicardial atrial pacemaker electrode, was used to verify the presence of JET. Detection of JET was made about 10 minutes after CICU admission. JET was defined as (1) a heart rate of 170 beats/min or more with a QRS complex morphology similar to the baseline normal sinus or atrial rhythm; (2) an atrioventricular dissociation with a ventricular rate higher than or equal to the atrial rate; (3) a ventricular/atrial association with a retrograde 1:1 or Wenckeback conduction. Preoperative variables including demographics, previous medical history, and previous electrocardiogram were collected. The classification of the surgery was assessed by the Aristotle level of complexity. (A complete list of the operations is available online in Table E1.) Intraoperative variables including CPB time, crossclamp time, and cardiac circulatory arrest time were recorded. Heart failure was defined by decreased ventricular function by echocardiography and/or clinical evidence of congestive heart failure. The patient's temperature, heart rate, central venous pressure, and mean blood pressure at the time of iMg blood samples were also recorded. Postoperative ventricular function assessed by echocardiography at CICU arrival, mechanical ventilation time, PRISM III score, CICU length of stay, hospital length of stay, and discharge status were also noted.

\section{Statistical Analysis}

The analysis was conducted on an intention-to-treat basis. Before the analysis, data were checked to identify any data entry error or confirm the outlier values. Data were stored electronically and were analyzed with SPSS 15.0 software (www.spss.com), STATA 10 and R version 2.6.0 (http://www.r-project.org). We used the Kruskal-Wallis test for continuous 
TABLE 1. Baseline demographic and medical history characteristics by study group

\begin{tabular}{|c|c|c|c|c|}
\hline \multirow[b]{2}{*}{ Characteristics } & \multicolumn{3}{|c|}{ Study group } & \multirow[b]{2}{*}{$P$ value* } \\
\hline & Group 1: Placebo $(n=29)$ & Group 2: $\mathrm{Mg}=25 \mathrm{mg} / \mathrm{kg}(\mathrm{n}=30)$ & Group 3: $\mathrm{Mg}=50 \mathrm{mg} / \mathrm{kg}(\mathrm{n}=40)$ & \\
\hline \multicolumn{5}{|l|}{ Age (y) } \\
\hline Median (range) & $3(0-17)$ & $1.54(0-17)$ & $1.37(0-11)$ & .34 \\
\hline \multicolumn{5}{|l|}{ Weight $(\mathrm{kg})$} \\
\hline Median (range) & $14.6(2.3-69)$ & $8.1(2.1-85)$ & $7.0(1.4-51)$ & .20 \\
\hline \multicolumn{5}{|l|}{$\operatorname{BSA}\left(\mathrm{m}^{2} / \mathrm{kg}\right)$} \\
\hline Median (range) & $0.6(0.18-1.7)$ & $0.4(0.17-1.98)$ & $0.36(0.14-1.4)$ & .21 \\
\hline \multicolumn{5}{|l|}{ Gender $(\mathrm{n} / \%)$} \\
\hline Female & $11 / 37.9$ & $17 / 56.7$ & $18 / 45.0$ & .34 \\
\hline Male & $18 / 62.1$ & $13 / 43.3$ & $22 / 55.0$ & \\
\hline Congenital anomalies $(\mathrm{n} / \%)$ & $0 / 0$ & $1 / 3.3$ & $3 / 7.5$ & .38 \\
\hline Down syndrome $(\mathrm{n} / \%)$ & $2 / 6.9$ & $6 / 20$ & $3 / 7.5$ & .23 \\
\hline DiGeorge syndrome $(\mathrm{n} / \%)$ & $1 / 3.4$ & $2 / 6.7$ & $1 / 2.5$ & .82 \\
\hline Neurologic disease (n/\%) & $4 / 13.8$ & $2 / 6.7$ & $2 / 5.0$ & .48 \\
\hline Redo (n/\%) & $14 / 48.3$ & $11 / 36.7$ & $11 / 27.5$ & .2 \\
\hline \multicolumn{5}{|l|}{ Aristotle (n/\%) } \\
\hline 1 & $4 / 14.3$ & $3 / 10.0$ & $8 / 20.0$ & .24 \\
\hline 2 & $6 / 21.4$ & $11 / 36.7$ & $14 / 35.0$ & \\
\hline 3 & $14 / 50.0$ & $14 / 46.7$ & $10 / 25.0$ & \\
\hline 4 & $4 / 14.3$ & $2 / 6.7$ & $8 / 20.0$ & \\
\hline Cardiac failure $(\mathrm{n} / \%)$ & $6 / 20.7$ & $8 / 26.7$ & $7 / 17.5$ & .64 \\
\hline Pulmonary hypertension (n/\%) & $2 / 6.9$ & $6 / 20.0$ & $4 / 10.0$ & .3 \\
\hline Asthma (n/\%) & $2 / 6.9$ & $0 / 0$ & $5 / 12.5$ & .11 \\
\hline Renal failure (n/\%) & $1 / 3.4$ & $0 / 0$ & $2 / 5$ & .63 \\
\hline Cardiogenic shock (n/\%) & $3 / 10.3$ & $1 / 3.3$ & $2 / 5$ & .58 \\
\hline Sinus rhythm & 28/96.6 & $28 / 93.3$ & $38 / 95$ & 1.0 \\
\hline \multicolumn{5}{|l|}{ CPB time (min) } \\
\hline Median (range) & $59(32-184)$ & $74.5(30-235)$ & $70.5(15-255)$ & .5 \\
\hline
\end{tabular}

variables and $\chi^{2}$ or Fisher's exact tests for categorical variables to compare demographics and medical history characteristics between study groups. Fisher's exact test was used to compare the proportion of hypomagnesemia between the study groups. One-way analysis of variance was performed to compare the average levels of $\mathrm{iMg}$ at each point in time by study groups, using Bonferroni test for multiple comparisons. Fisher's exact test was used to compare the proportion of JET by study group and to determine whether the proportion of JET after surgery was significantly different by preoperative covariates. For those covariates that were found to be significantly associated with the presence of JET in this univariate analysis, a stratified analysis was performed to determine whether there was an association between the presence of JET after surgery and study groups stratified by these covariates. A log transformation was used because the distribution of variable CICU length of stay was highly skewed. Linear regression was used to compare the CICU length of stay among the 3 treatment arms. Poisson regression was used in the analysis of the PRISM score.

\section{RESULTS}

\section{Study Population}

Between February 2005 and August 2006, 99 patients were included in the study. Twenty-nine patients were randomly assigned to group 1 (placebo group), 30 patients to group 2 (receiving $25 \mathrm{mg} / \mathrm{kg}$ of $\mathrm{MgSO}_{4}$ ), and 40 patients to group 3 (receiving $50 \mathrm{mg} / \mathrm{kg}$ of $\mathrm{MgSO}_{4}$ ). The 3 groups of patients were similar in regard to patient demographics and preoperative and intraoperative variables (Table 1).

\section{Analysis of iMg Level and Incidence of Hypomagnesemia}

The average of $\mathrm{iMg}$ level at each time point was compared among the study groups. The levels of $\mathrm{iMg}$ at time 1 and time 2 were not significantly different among the 3 groups ( $P=.9$ and .5 , respectively). In the 3 study groups, iMg level significantly increased at time 3 (10 minutes after the administration of the study) and decreased again at time 4 (CICU admission) (Figure 1). At time 3, the average of iMg level in group $3\left(50 \mathrm{mg} / \mathrm{kg}\right.$ of $\left.\mathrm{MgSO}_{4}\right)$ was significantly greater than the levels in groups 1 and 2 (group 1, $0.56 \pm 0.16$; group 2, $0.73 \pm 0.21$; group $3,0.93 \pm 0.24 ; P=.0001$ ). Moreover, both groups 2 and 3 had significantly greater levels of iMg at time 4 than did the placebo (group 1, $0.51 \pm 0.07$; group $2,0.57 \pm 0.09$; group 3, $0.59 \pm 0.09 ; P=.0001$ ) (Table 2).

Hypomagnesemia was common, and no significant difference was found among the study groups before $\mathrm{CPB}$ (group $1,75 \%$; group $2,86.2 \%$; group $3,83.3 \% ; P=.6$ ) (data available online in Table E2). The proportion of hypomagnesemia was not significantly different at time 2 among the study groups, just before the solution administration (group 1, 92.6\%; group 2, 86.7\%; group 3, 88.9\%; $P=$ $.8)$. There were significant differences in the proportion of hypomagnesemia among the 3 groups at time 3 (group 1, 


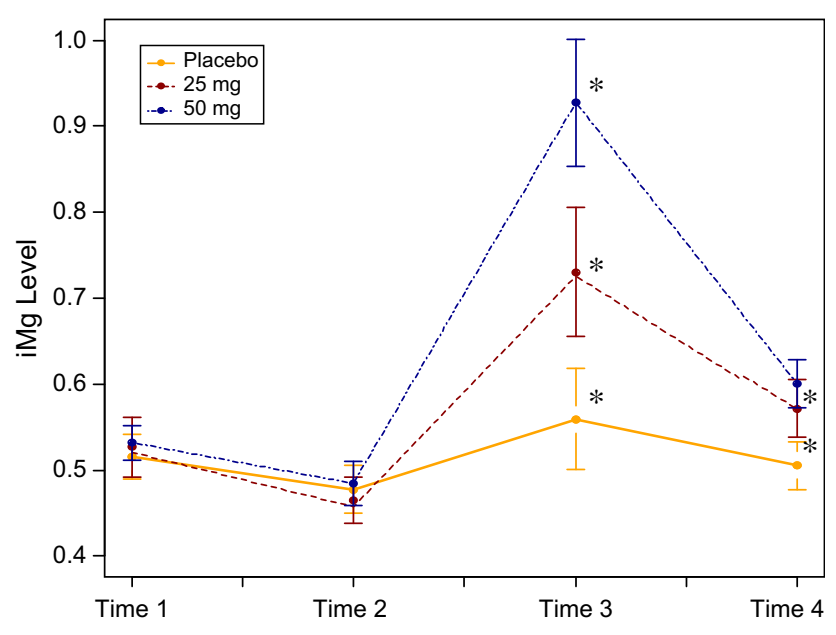

FIGURE 1. Average ionized magnesium $(i M g)$ level by study group over time. Time 1, Baseline; time 2,10minutes after initiation of $\mathrm{CPB}$; time 3, 10 minutes after study solution; time 4 , At the $\mathrm{CICU}$ admission. *P value $<.05$.

$60.7 \%$; group 2, 27.6\%; group 3, $13.2 \% ; P<.01)$. Both groups 1 and 2 reported significantly greater proportion of hypomagnesemia than group 3 at time 3 . The same pattern could be noticed at time 4; however, the $P$ value was marginally significant (group $1,77.8 \%$; group $2,63.0 \%$; group 3 , $47.4 \% ; P=.05)$ (data available online in Table E2).

\section{Analysis of JET}

Univariate analysis. The total incidence of JET was 7.0\% for the 99 patients. The unadjusted analysis showed that there were significant differences in the proportion of JET among the 3 study groups. Group 1 (placebo group) patients had a significantly greater proportion of JET than group 2 and group 3 patients (group 1, $\mathrm{n}=5[17.9 \%$ ]; group 2, $\mathrm{n}$ $=2[6.7 \%]$; group $3, \mathrm{n}=0[0 \%] ; P=.009)$. Both age and Aristotle score are also marginally associated with the occurrence of JET. Patients who were 1 month of age or less were more likely to have JET after surgery than were the other age categories ( $\leq 1$ month, $21.4 \% ; 1$ month to 1 year, $7.1 \%$; $>1$ year, $3.6 \% ; P=.06)$. Moreover, patients with an Aristotle score of 4 or more were more likely to have JET than were those with a score of less than 4 $(21.3 \%$ vs $4.8 \% ; P=.06)$. History of cardiac failure before the operation was found to be significantly associated with the occurrence of JET after the operation: $19.1 \%$ of the patients who had cardiac failure before surgery had JET compared with $3.9 \%$ of those who did not have a history of cardiac failure $(P=.03)$. CPB time was marginally associated with the development of JET $(P=.05)$. In addition, 5 $(71 \%)$ of 7 patients with JET were hypomagnesemic at the CICU admission.

Stratified analysis. We analyzed the association between the occurrence of JET and study groups stratified by Aristo-
TABLE 2. Ionized magnesium level at each time point by study groups

\begin{tabular}{lcccc} 
& \multicolumn{2}{c}{ Ionized magnesium level by study group (mean \pm SD) } & \\
\cline { 2 - 4 } $\begin{array}{c}\text { Time } \\
\text { points }\end{array}$ & $\begin{array}{c}\text { Group 1: } \\
\text { Placebo }\end{array}$ & $\begin{array}{c}\text { Group 2: } \\
\mathbf{M g}=\mathbf{2 5} \mathbf{~ m g / k g}\end{array}$ & $\begin{array}{c}\text { Group 3: } \\
\mathbf{M g}=\mathbf{5 0} \mathbf{~ m g} / \mathbf{k g}\end{array}$ & $\begin{array}{c}\boldsymbol{P} \\
\text { value* }\end{array}$ \\
\hline $\mathrm{T} 1$ & $\mathrm{n}=28$ & $\mathrm{n}=29$ & $\mathrm{n}=36$ & .9 \\
& $0.52 \pm 0.07$ & $0.52 \pm 0.10$ & $0.53 \pm 0.06$ & \\
$\mathrm{~T} 2$ & $\mathrm{n}=27$ & $\mathrm{n}=30$ & $\mathrm{n}=36$ & .5 \\
& $0.48 \pm 0.07$ & $0.46 \pm 0.08$ & $0.48 \pm 0.08$ & \\
$\mathrm{~T} 3$ & $\mathrm{n}=28$ & $\mathrm{n}=29 \dagger$ & $\mathrm{n}=38 \dagger, \ddagger$ & .0001 \\
& $0.56 \pm 0.16$ & $0.73 \pm 0.21$ & $0.93 \pm 0.24$ & \\
$\mathrm{~T} 4$ & $\mathrm{n}=27$ & $\mathrm{n}=27 \dagger$ & $\mathrm{n}=38 \dagger$ & .0001 \\
& $0.51 \pm 0.07$ & $0.57 \pm 0.09$ & $0.59 \pm 0.09$ & \\
\hline
\end{tabular}

$T 1$, Before surgery; $T 2$, during surgery and before trial intervention; $T 3$, during surgery and after trial intervention; $T 4$, after surgery at cardiac intensive care unit; $S D$, standard deviation. *One-way analysis of variance: †Differed significantly from placebo; $\ddagger$ differed significantly from $\mathrm{mg}=25 \mathrm{mg} / \mathrm{kg}$.

tle score and age group (Table 3). Other potential confounders, including potassium, calcium, glucose, base excess, and $\mathrm{pH}$ levels at each time point were similarly distributed among the 3 study groups.

\section{Analysis of CICU Length of Stay}

Both treatment groups tended to spend a longer time in the CICU than the placebo group; however, this difference was not statistically significant (group $1,1.08 \pm 0.75$ days; group $2,1.30 \pm 1.13$ days; group $3,1.23 \pm 0.91$ days; $P=.7$ ). We analyzed the main covariates that were significantly or marginally significantly associated with CICU length of stay in a univariate linear regression. Positive significant associations were reported between Aristotle score, the history of cardiac failure, CPB time, and CICU length of stay. After adjusting for $\mathrm{CPB}$ time, cardiac failure, and Aristotle score, the CICU length of stay in each of the 2 treatment groups was not significantly different from that in the placebo group (data available online in Table E3). CPB time, Aristotle score of 4 or more, and a history of cardiac failure were found to be independent predictors of the CICU length of stay from the multivariate model.

\section{Analysis of PRISM Score}

Aristotle scores and CPB times of more than $60 \mathrm{~min}$ utes were found to be significantly associated with PRISM score $(P=.02$ and .01 , respectively). Although both treatment groups had higher PRISM scores, the scores were not statistically significant compared with placebo $(P=.5)$. Even after adjusting the effect of asthma, Aristotle score, CPB time (dichotomized into $\leq 60$ minutes or $>60$ minutes), and using a multivariate Poisson regression, the PRISM score did not significantly differ among the treatment groups. History of asthma and CPB time of more than 60 minutes were found to be independently associated with a greater PRISM score (data available online in Table E4). 
TABLE 3. Proportion distribution of JET arrhythmia by study groups stratified by significant and marginal significant covariates

\begin{tabular}{|c|c|c|c|c|}
\hline & \multicolumn{3}{|c|}{ Study group } & \multirow[b]{2}{*}{$\begin{array}{c}P \\
\text { value* }\end{array}$} \\
\hline & $\begin{array}{l}\text { Group 1: } \\
\text { Placebo }\end{array}$ & $\begin{array}{c}\text { Group 2: } \\
\mathrm{Mg}=25 \mathrm{mg} / \mathrm{kg}\end{array}$ & $\begin{array}{c}\text { Group 3: } \\
\mathrm{Mg}=\mathbf{5 0} \mathrm{mg} / \mathrm{kg}\end{array}$ & \\
\hline \multicolumn{5}{|l|}{ Age } \\
\hline$\leq 1 \mathrm{mo}(\mathrm{n})$ & $5 \dagger$ & 3 & 6 & $.03 *$ \\
\hline JET yes (n) & (3) $60 \%$ & (0) $0 \%$ & (0) $0 \%$ & \\
\hline $1 \mathrm{mo}$ to $1 \mathrm{y}(\mathrm{n})$ & 4 & 11 & 13 & .1 \\
\hline JET yes (n) \% & (1) $25 \%$ & (1) $9.1 \%$ & (0) $0 \%$ & \\
\hline$>1$ y $(\mathrm{n})$ & 19 & 16 & 21 & .5 \\
\hline JET yes (n) \% & (1) $5.3 \%$ & (1) $6.3 \%$ & (0) $0 \%$ & \\
\hline \multicolumn{5}{|l|}{ Aristotle score } \\
\hline$<4(\mathrm{n})$ & 23 & 28 & 32 & .06 \\
\hline JET yes (n) \% & (3) $13.0 \%$ & (1) $3.6 \%$ & (0) $0 \%$ & \\
\hline$\geq 4(\mathrm{n})$ & 4 & 2 & 8 & .07 \\
\hline JET yes (n) \% & (2) $50 \%$ & (1) $50 \%$ & (0) $0 \%$ & \\
\hline \multicolumn{5}{|l|}{ Cardiac failure } \\
\hline Yes (n) & 6 & 8 & 7 & .06 \\
\hline JET yes (n) \% & (2) $33.3 \%$ & (2) $25.0 \%$ & (0) $0 \%$ & \\
\hline No $(n)$ & 22 & 22 & 33 & $.04 *$ \\
\hline JET yes (n) \% & (3) $13.6 \%$ & (0) $0 \%$ & (0) $0 \%$ & \\
\hline \multicolumn{5}{|c|}{ CPB time (min) } \\
\hline$\leq 60(\mathrm{n})$ & 15 & 10 & 17 & 6 \\
\hline JET yes (n) \% & (1) $6.7 \%$ & (0) $0 \%$ & (0) $0 \%$ & \\
\hline$>60(n)$ & 13 & 20 & 23 & .01 \\
\hline JET yes (n) & (4) $30.8 \%$ & (2) $10 \%$ & (0) $0 \%$ & \\
\hline
\end{tabular}

$J E T$, Junctional ectopic tachycardia; $C P B$, cardiopulmonary bypass. *Fisher's exac test; $\nmid \mathrm{n}$ is the total of column variable.

\section{Adverse Effects}

No episodes of severe bradycardia or hypotension were reported. The incidences of renal failure or cardiac dysfunction were similar in the 3 study groups.

\section{DISCUSSION}

In this study, we found that in children undergoing cardiac surgery with $\mathrm{CPB}$, the administration of a single dose of $\mathrm{MgSO}_{4}$ during CPB reduces the incidence of hypomagnesemia by $30 \%$ and also decreases the incidence of postoperative JET at the time of CICU admission. In addition, this effect of magnesium seems to be dose related. None of the patients who received $50 \mathrm{mg} / \mathrm{kg}$ of $\mathrm{MgSO}_{4}$ had JET as detected on arrival in the CICU, whereas the incidence of JET was $6.7 \%$ in patients who received $25 \mathrm{mg} / \mathrm{kg}$ of $\mathrm{MgSO}_{4}$ and $17.9 \%$ in patients who received placebo. The overall incidence of JET in our study population was $6.9 \%$, comparable with the same incidence described in previous reports. ${ }^{13,14}$

\section{Level of iMg and Hypomagnesemia}

Our data suggest that supplementation of magnesium during $\mathrm{CPB}$ reverses hypomagnesemia and reduces the frequency of JET as detected on arrival in the CICU.
This finding supports the notion that iMg levels during CPB are clinically relevant and hypomagnesemia should be aggressively treated to potentially prevent JET in the immediate postoperative period. Although we do not know the specific mechanism by which the appropriate magnesium level during CPB prevents JET, we speculate that magnesium stabilizes the myocyte ionic channels leading to myocardial protection and electrical equilibrium. The critical $\mathrm{iMg}$ level that protects the myocardium during $\mathrm{CPB}$ is unknown, but it may vary among different pathologic conditions, surgical strategies, and degrees of injury.

As in previous studies, ${ }^{12}$ our data at the time of the CICU admission showed that the frequency of hypomagnesemia was marginally higher between placebo and magnesium groups. We speculate that this difference may be clinically insignificant. This little difference may be explained by multiple factors that occur after CPB and influence whole blood magnesium levels, such as ultrafiltration, intravenous fluids, blood transfusions, and drugs. ${ }^{14-16}$

Preoperative factors may include the fact that many of those cardiac patients are receiving medications that increase the renal loses of magnesium, such as diuretics and digitalis. Moreover, during the operation, patients are exposed to hemodilution, blood loss, blood transfusions, and an increase of catecholamines that cause chelation of magnesium. All of these are factors that contribute to the decrease in plasma magnesium levels. In addition, during surgery, continuous hemofiltration, modified ultrafiltration, and administration of large doses of calcium and diuretics can all cause depletion of magnesium. Other factors causing hypomagnesemia include the intracellular elimination shifts induced by the extracorporeal circulation and the decrease in body temperature during surgery. ${ }^{5,15-20}$ As expected, in both groups of patients receiving magnesium, the levels of $\mathrm{iMg}$ increased after the administration of the $\mathrm{MgSO}_{4}$. This increase was higher in the group receiving $50 \mathrm{mg} / \mathrm{kg}$ of $\mathrm{MgSO}_{4}$ where the highest levels of iMg were close to the upper level of normal for age. In the placebo group, there was also a slight elevation in the levels of iMg at time 3. This effect may be related to the hemoconcentration during the rewarming period of CPB and to the administration of the cardioplegic solution containing magnesium. However, in our opinion, the effect of the cardioplegic solution should not be significant because the solution used is a custom prepared solution containing a low concentration of magnesium. We observed a progressive decrease in the iMg level in the 3 groups during CPB after time 3 (approximately 10 minutes after the administration of the study medication) and at CICU arrival. This reduction may be explained by several factors occurring during the operation, such as the administration of diuretics, transfusion of blood products, increase in exogenous catecholamines, and the modified ultrafiltration performed at the end of $\mathrm{CPB}$. Although iMg levels are similar between both magnesium groups at CICU arrival, these 
levels are significantly higher than those of the placebo group, indicating a beneficial effect of the administration of $\mathrm{MgSO}_{4}$ during CPB.

\section{JET and Antiarrhythmic Effect of Magnesium}

The presence of early postoperative arrhythmias is a predictor for late complications such as ventricular dysfunction, late arrhythmias, and late mortality. ${ }^{2,14,21,22}$ Thus, the prevention of these arrhythmias will improve the postoperative course and outcomes. In adults after cardiac surgery, one of the most common supraventricular arrhythmias is atrial fibrillation. Several studies have demonstrated the role of hypomagnesemia in the development of postoperative atrial fibrillation and the prophylactic effect of the supplementation with $\mathrm{MgSO}_{4}$ during or after surgery. ${ }^{23}$ In the early postoperative period after pediatric cardiac surgery, one of the most common arrhythmias is JET. The occurrence of postoperative JET has been associated with longer CICU stay and longer mechanical ventilation time. Etiologic factors related to the development of JET are not completely clear. ${ }^{2,13,14}$

Magnesium is the second most important intracellular divalent cation and is an obligatory cofactor for many of the enzyme systems involved in energy metabolism. Magnesium also acts as a natural calcium antagonist, regulating calcium access into the cell and contributing to the generation and regulation of ion channel transport processes in the myocytes. The antiarrhythmic effects of magnesium in polymorphic ventricular tachyarrhythmia have been attributed to a decrease in inward calcium current via L-type calcium channels and to the stabilization of the membrane potential by facilitation of potassium entry into the cells, from the enhancement of sodium-potassium adenosine triphosphatase as a cofactor. Therefore, magnesium increases the negative membrane resting potential reducing myocardial excitability. Magnesium infusion during supraventricular tachycardia has been shown to prolong tachycardia cycle length by delaying the atrioventricular nodal conduction. It increases the relative refractory period and decreases the vulnerable period, reducing the risk for re-entry. ${ }^{4,24-26}$ Myocardial dysfunction after surgery is a risk factor for the development of JET according to previous studies. ${ }^{7,13,14}$ Newborns and children are more susceptible to arrhythmias and myocardial dysfunction after cardiac surgery. In the immature myocardium, most of the calcium required for myocardial contraction is provided by the sarcoplasmic reticulum, which is still underdeveloped and has a reduced storage capacity for calcium. This immature heart is more sensitive to extracellular calcium levels than the mature myocardium. JET is generated by an enhanced automaticity or triggered activity on an ectopic focus within the atrioventricular node or the proximal His bundle. ${ }^{25}$ Conditions that increase the likelihood of enhanced abnormal automaticity are very common during CPB and include ischemia, electrolyte imbalances, catechol- amine excess, and certain drug toxicities. ${ }^{27}$ The prophylactic effect of magnesium is related to its capacity to decrease the catecholamine release from the adrenal medulla and adrenergic nerve endings. ${ }^{26}$ In addition, animal studies have shown that $\mathrm{MgSO}_{4}$ attenuates the degree of myocardial necrosis and plays a cardioprotective role in ischemia-reperfusion injury. The beneficial effect of the administration of $\mathrm{MgSO}_{4}$ during the reperfusion period of CPB could result from the maintenance of the stabilization of the membrane and the reduction of the vulnerability to automatic and re-entry mechanism. ${ }^{11}$ Hypomagnesemia has also been associated with the presence of JET in previous studies. Supplementation with $\mathrm{MgSO}_{4}$ during CPB reduces incidence of all arrhythmias in adults and children. Dittrich and associates ${ }^{28}$ in their randomized clinical trial in 131 patients, demonstrated the association between the supplementation with magnesium and a decrease in the overall incidence of postoperative arrhythmias in children and adults after surgery for congenital heart disease. They used an infusion of magnesium chloride after $\mathrm{CPB}$ that can cause less toxicity than $\mathrm{MgSO}_{4}$. They analyzed serum and iMg levels and the presence of arrhythmias at the CICU. There are some important limitations of this study that should be highlighted, such as that the assignment to study groups was not blinded in the moment of assessment of the occurrence of arrhythmias. They also used a cardioplegic solution with a high content of magnesium, which may explain the lower incidence of hypomagnesemia at CICU admission, compared with our findings. Dorman and associates $^{3}$ also developed a double-blind clinical trial in 28 pediatric patients after surgery for congenital heart disease. On this occasion, the group receiving $30 \mathrm{mg} / \mathrm{kg}$ of $\mathrm{MgSO}_{4}$ administered in a single bolus at the end of CPB was compared with a placebo group. The fact that they analyzed the serum levels of total magnesium and not the iMg levels could explain the lower incidence of hypomagnesemia is this study. Previous studies have demonstrated that patients might have ionized hypomagnesemia with normal serum levels of total magnesium. ${ }^{12,15,20}$ In this study, physicians were unblinded if patients required antiarrhythmic therapy. The study was designed for 100 patients and was stopped prematurely after finding 4 cases of JET, which were all in the placebo group. Any of those studies were developed specifically for the detection of incidence of JET; however, these 2 well-designed studies consistently demonstrated a decrease in the incidence of postoperative arrhythmias with the administration of magnesium. The supplementation of magnesium was performed in both cases after CPB. As previously described, hypomagnesemia is a persistent finding all through $\mathrm{CPB}$ and the correction of it at that point can be critical to reach an adequate myocardial protection and consequently achieve a reduction of postoperative arrhythmias. We consider that the administration of a single dose of $\mathrm{MgSO}_{4}$ during CPB is a safer practice and can have a protective effect at the moment of heart reperfusion. 
Existing studies have reported several consistent risk factors associated with the presence of JET, including younger age at the time of surgery, longer CPB duration, higher surgical complexity, use of high inotropic support, underlying congenital heart disease, and extension of the myocardial injury. ${ }^{2}$ In our stratified analysis, we found younger age $(<1$ month), higher complexity of surgery (Aristotle score $\geq 4$ ), and previous history of cardiac failure as significant or marginally significant covariates associated with the development of JET, corroborating those previous findings. However, we did not find any significant difference in patients with longer CPB. We also did not find any significant difference in the level of other electrolytes, the intraoperative use of inotropic support, and time of rewarming.

\section{CICU Length of Stay and PRISM Score}

In a previous study, patients older than 1 month of age with hypomagnesemia during CPB had a longer period of mechanical ventilation, longer CICU stay, and a tendency for a higher PRISM III score. ${ }^{12}$ We did not have the same finding in our study; however, this can be a consequence of the sample size. We found as independent significant predictors for the PRISM score asthma and longer CPB, whereas history of cardiac failure, complexity of surgery, and CPB time were found as independent predictors for longer CICU stay.

\section{Limitations of the Study}

Even though baseline characteristics and surgical complexity were equal in our study groups, this population does not represent all the pediatric cardiac surgical patients who may be at risk for postoperative JET. For example, patients requiring emergency surgery and patients who were critically ill (preoperatively) were not included in the study. In addition, our study was not designed to evaluate the incidence of JET after CICU admission. Thus the incidence of JET and/or other arrhythmias over a prolonged postoperative period was not evaluated. Another limitation of the study is the lack of available tools to measure intracellular activity of the magnesium. Intracellular magnesium may be more of an indicator of hypomagnesemia and arrhythmias. The low incidence of JET limits the number of patients for analysis. A study with a large number of patients will be needed to validate our results.

\section{CONCLUSIONS}

This study suggests that $\mathrm{MgSO}_{4}$ supplementation during $\mathrm{CPB}$ reduces the incidence of hypomagnesemia and decreases the incidence of JET at the time of CICU admission. In addition, this effect seems to be dose related.

We thank those families who allowed us to include their children in our study. We also thank the pediatric cardiac perfusion team,
Don Koch, Don Malloney, and Kent Kelly; the pharmacists, Paul Hoffman and Jeniffer Wagner; and Tamara Maihle and all the staff in OR 22 and the CICU at Children's Hospital of Pittsburgh for their collaboration.

\section{References}

1. Roos-Hesselink JW, Karamermer Y. Significance of postoperative arrhythmias in congenital heart disease. Pacing Clin Electrophysiol. 2008;31(Suppl 1):S2-6.

2. Batra AS, Chun DS, Johnson TR, Maldonado EM, Kashyap BA, Maiers J, et al. A prospective analysis of the incidence and risk factors associated with junctional ectopic tachycardia following surgery for congenital heart disease. Pediatr Cardiol. 2006;27:51-5.

3. Dorman BH, Sade RM, Burnette JS, Wiles HB, Pinosky ML, Reeves ST, et al. Magnesium supplementation in the prevention of arrhythmias in pediatric patients undergoing surgery for congenital heart defects. Am Heart J. 2000;139: $522-8$

4. Noronha JL, Matuschak GM. Magnesium in critical illness: metabolism, assessment, and treatment. Intensive Care Med. 2002;28:667-79.

5. Inoue S, Akazawa S, Nakaigawa Y, Shimizu R, Seo N. Changes in plasma total and ionized magnesium concentrations and factors affecting magnesium concentrations during cardiac surgery. $J$ Anesth. 2004;18:216-9.

6. Booth JV, Phillips-Bute B, McCants CB, Podgoreanu MV, Smith PK, Mathew JP, et al. Low serum magnesium level predicts major adverse cardiac events after coronary artery bypass graft surgery. Am Heart J. 2003;145:1108-13.

7. Magnesium in Coronaries (MAGIC) Trial Investigators. Early administration of intravenous magnesium to high-risk patients with acute myocardial infarction in the Magnesium in Coronaries (MAGIC) Trial: a randomised controlled trial. Lancet. 2002;360:1189-96.

8. Miller S, Crystal E, Garfinkle M, Lau C, Lashevsky I, Connolly SJ. Effects of magnesium on atrial fibrillation after cardiac surgery: a meta-analysis. Heart. 2005;91:618-23.

9. Kohno H, Koyanagi T, Kasegawa H, Miyazaki M. Three-day magnesium administration prevents atrial fibrillation after coronary artery bypass grafting. Ann Thorac Surg. 2005;79:117-26.

10. Mayson SE, Greenspon AJ, Adams S, Decaro MV, Sheth M, Weitz HH, et al. The changing face of postoperative atrial fibrillation prevention: a review of current medical therapy. Cardiol Rev. 2007;15:231-41.

11. Shepherd J, Jones J, Frampton GK, Tanajewski L, Turner D, Price A. Intravenous magnesium sulphate and sotalol for prevention of atrial fibrillation after coronary artery bypass surgery: a systematic review and economic evaluation. Health Technol Assess. 2008;12: iii-iv, ix-95.

12. Munoz R, Laussen PC, Palacio G, Zienko L, Piercey G, Wessel DL. Whole blood ionized magnesium: age-related differences in normal values and clinical implications of ionized hypomagnesemia in patients undergoing surgery for congenital cardiac disease. J Thorac Cardiovasc Surg. 2000;119:891-8.

13. Andreasen JB, Johnsen SP, Ravn HB. Junctional ectopic tachycardia after surgery for congenital heart disease in children. Intensive Care Med. 2008; 34:895-902.

14. Azzam FJ, Fiore AC. Postoperative junctional ectopic tachycardia. Can J Anaesth. 1998;45:898-902.

15. Fiser RT, Torres A Jr, Butch AW, Valentine JL. Ionized magnesium concentrations in critically ill children. Crit Care Med. 1998;26:2048-52.

16. Hoshino K, Ogawa K, Hishitani T, Kitazawa R. Influence of heart surgery on magnesium concentrations in pediatric patients. Pediatr Int. 2003;45:39-44.

17. Fox ML, Burrows FA, Reid RW, Hickey PR, Laussen PC, Hansen DD. The influence of cardiopulmonary bypass on ionized magnesium in neonates, infants, and children undergoing repair of congenital heart lesions. Anesth Analg. 1997; 84:497-500.

18. Jian W, Su L, Yiwu L. The effects of magnesium prime solution on magnesium levels and potassium loss in open heart surgery. Anesth Analg. 2003;96: 1617-20, table of contents.

19. Maggioni A, Orzalesi M, Mimouni FB. Intravenous correction of neonatal hypomagnesemia: effect on ionized magnesium. J Pediatr. 1998;132:652-5.

20. Lu CY, Tan PH, Lin SH, Tsai SK, Lin SM, Mao CC, et al. Body weight-related ionized hypomagnesemia in pediatric patients undergoing cardiopulmonary bypass for surgical repair of congenital cardiac defects. J Clin Anesth. 2003;15: 189-93.

21. Deal BJ, Mavroudis C, Backer CL. The role of concomitant arrhythmia surgery in patients undergoing repair of congenital heart disease. Pacing Clin Electrophysiol. 2008;31(Suppl 1):S13-6. 
22. Dodge-Khatami A, Miller OI, Anderson RH, Goldman AP, Gil-Jaurena JM, Elliott MJ, et al. Surgical substrates of postoperative junctional ectopic tachycardia in congenital heart defects. J Thorac Cardiovasc Surg. 2002;123:624-30.

23. Shiga $T$, Wajima $Z$, Inoue $T$, Ogawa $R$. Magnesium prophylaxis for arrhythmias after cardiac surgery: a meta-analysis of randomized controlled trials. Am J Med. 2004; 117:325-33

24. Stiles MK, Sanders P, Disney P, Brooks A, John B, Lau DH, et al. Differential effects of intravenous magnesium on atrioventricular node conduction in supraventricular tachycardia. Am J Cardiol. 2007;100:1249-53.

25. Lau EW. Infraatrial supraventricular tachycardias: mechanisms, diagnosis, and management. Pacing Clin Electrophysiol. 2008;31:490-8.
26. Chakraborti S, Chakraborti T, Mandal M, Mandal A, Das S, Ghosh S. Protective role of magnesium in cardiovascular diseases: a review. Mole Cell Biochem. 2002; 238:163-79.

27. Rekawek J, Kansy A, Miszczak-Knecht M, Manowska M, Bieganowska K, Brzezinska-Paszke M, et al. Risk factors for cardiac arrhythmias in children with congenital heart disease after surgical intervention in the early postoperative period. J Thorac Cardiovasc Surg. 2007;133:900-4.

28. Dittrich S, Germanakis J, Dahnert I, Stiller B, Dittrich H, Vogel M, et al. Randomised trial on the influence of continuous magnesium infusion on arrhythmias following cardiopulmonary bypass surgery for congenital heart disease. Intensive Care Med. 2003;29:1141-4. 
TABLE E1. Surgical procedures and frequency of JET

\begin{tabular}{|c|c|c|c|c|c|c|c|}
\hline \multirow[b]{2}{*}{ Surgery } & \multicolumn{2}{|c|}{ Group 1: Placebo JET } & \multicolumn{2}{|c|}{ Group 2: $25 \mathrm{mg} / \mathrm{kg} \mathrm{JET}$} & \multicolumn{2}{|c|}{ Group 3: $50 \mathrm{mg} / \mathrm{kg} \mathrm{JET}$} & \multirow{2}{*}{$\frac{\text { Total JET }}{Y=1, N=0}$} \\
\hline & $\mathbf{Y}=\mathbf{1}$ & $\mathbf{N}=\mathbf{0}$ & $\mathbf{Y}=\mathbf{1}$ & $\mathbf{N}=\mathbf{0}$ & $\mathbf{Y}=\mathbf{1}$ & $\mathbf{N}=\mathbf{0}$ & \\
\hline & 1 & 0 & 1 & 0 & 1 & 0 & \\
\hline Fontan & 1 & 8 & 0 & 2 & 0 & 2 & 1 \\
\hline Sano & 1 & 1 & 0 & 1 & 0 & 0 & 1 \\
\hline TOF repair & 1 & 2 & 0 & 6 & 0 & 4 & 1 \\
\hline ASD closure & 0 & 2 & 0 & 1 & 0 & 4 & 0 \\
\hline Mitral valve repair & 0 & 0 & 0 & 1 & 0 & 1 & 0 \\
\hline VSD closure & 0 & 2 & 1 & 4 & 0 & 5 & 1 \\
\hline Ross procedure & 0 & 0 & 0 & 0 & 0 & 1 & 0 \\
\hline Lung transplant & 0 & 0 & 1 & 0 & 0 & 0 & 1 \\
\hline Septostomy & 0 & 1 & 0 & 0 & 0 & 0 & 0 \\
\hline RV-PA conduit & 1 & 0 & 0 & 1 & 0 & 1 & 1 \\
\hline RVOT repair & 0 & 0 & 0 & 2 & 0 & 1 & 0 \\
\hline AVC repair & 0 & 1 & 0 & 3 & 0 & 5 & 0 \\
\hline Aortic arch and VSD repair & 1 & 0 & 0 & 1 & 0 & 1 & 1 \\
\hline PAPVC repair & 0 & 0 & 0 & 1 & 0 & 2 & 0 \\
\hline Subaortic membrane resection & 0 & 2 & 0 & 2 & 0 & 4 & 0 \\
\hline Subaortic stenosis repair & 0 & 0 & 0 & 1 & 0 & 0 & 0 \\
\hline VSD and ASD closure & 0 & 1 & 0 & 0 & 0 & 1 & 0 \\
\hline Aortic aneurysm repair & 0 & 0 & 0 & 0 & 0 & 1 & 0 \\
\hline TOF,VSD-MAPCA repair & 0 & 0 & 0 & 1 & 0 & 0 & 0 \\
\hline Arterial switch & 0 & 0 & 0 & 0 & 0 & 4 & 0 \\
\hline Glenn & 0 & 1 & 0 & 0 & 0 & 0 & 0 \\
\hline Truncus repair & 0 & 0 & 0 & 0 & 0 & 1 & 0 \\
\hline Aortic translocation & 0 & 0 & 0 & 0 & 0 & 1 & 0 \\
\hline Aortic valve repair & 0 & 0 & 0 & 1 & 0 & 0 & 0 \\
\hline TAPVR & 0 & 0 & 0 & 0 & 0 & 1 & 0 \\
\hline Mustard modified & 0 & 1 & 0 & 0 & 0 & 0 & 0 \\
\hline
\end{tabular}

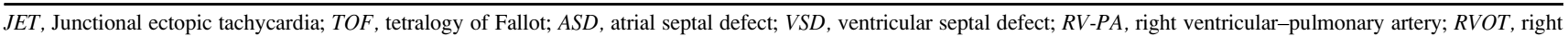
ventricular outflow tract; $A V C$, atrioventricular canal; $P A P V C$, partial anomalous pulmonary venous connection; MAPCA, major aortopulmonary collateral artery; TAPVR, total anomalous pulmonary venous return.

TABLE E2. Hypomagnesemia* at each time point by study groups

\begin{tabular}{|c|c|c|c|c|}
\hline \multirow[b]{2}{*}{$\begin{array}{c}\text { Time } \\
\text { points } \dagger\end{array}$} & \multicolumn{3}{|c|}{ Proportion of hypomagnesemia (\%) } & \multirow[b]{2}{*}{$\begin{array}{c}P \\
\text { value } \ddagger\end{array}$} \\
\hline & $\begin{array}{c}\text { Group 1: } \\
\text { Placebo }\end{array}$ & $\begin{array}{c}\text { Group 2: } \\
\mathrm{Mg}=25 \mathrm{mg} / \mathrm{kg}\end{array}$ & $\begin{array}{c}\text { Group 3: } \\
\mathbf{M g}=\mathbf{5 0} \mathrm{mg} / \mathrm{kg} \\
\end{array}$ & \\
\hline \multirow[t]{2}{*}{$\mathrm{T} 1$} & $\mathrm{n}=28$ & $\mathrm{n}=29$ & $\mathrm{n}=36$ & .6 \\
\hline & $75 \%$ & $86.2 \%$ & $83.3 \%$ & \\
\hline \multirow[t]{2}{*}{$\mathrm{T} 2$} & $\mathrm{n}=27$ & $\mathrm{n}=30$ & $\mathrm{n}=36$ & .8 \\
\hline & $92.6 \%$ & $86.7 \%$ & $88.9 \%$ & \\
\hline \multirow[t]{2}{*}{$\mathrm{T} 3$} & $\mathrm{n}=28$ & $\mathrm{n}=29$ & $\mathrm{n}=38$ & $<.000001 *$ \\
\hline & $60.7 \%$ & $27.6 \%$ & $13.2 \%$ & \\
\hline \multirow[t]{2}{*}{$\mathrm{T} 4$} & $\mathrm{n}=27$ & $\mathrm{n}=27$ & $\mathrm{n}=38$ & .05 \\
\hline & $77.8 \%$ & $63.0 \%$ & $47.4 \%$ & \\
\hline
\end{tabular}

*Presence of hypomagnesemia was based on ionized magnesium level adjusted for age as follows: for age $\leq 1 \mathrm{month}: 0.46 \mathrm{mmol} / \mathrm{L}(0.43-0.49 \mathrm{mmol} / \mathrm{L})$, for age 1 month to 1 year: $0.72 \mathrm{mmol} / \mathrm{L}(0.67-0.74 \mathrm{mmol} / \mathrm{L})$, for age 1 year to 19 years: $0.63 \mathrm{mmol} / \mathrm{L}$ (0.59-0.67), for age $\geq 20$ years: $0.53 \mathrm{mmol} / \mathrm{L}(0.51-0.54)$. $\dagger \mathrm{T} 1$, Before surgery; $\mathrm{T} 2$, during surgery and before trial intervention; $\mathrm{T} 3$, during surgery and after trial intervention; T4, after surgery at cardiac intensive care unit. †̣Fisher’s exact test.
TABLE E3. Multivariate linear regression to test of length of stay in cardiac intensive care unit* was significantly associated with study group after adjusting for study covariates

\begin{tabular}{|c|c|c|c|}
\hline & Regression coefficient & $95 \%$ CI & $\begin{array}{c}P \\
\text { value* }\end{array}$ \\
\hline$P$ value & $<.0001$ & & \\
\hline$R^{2}$ & 0.38 & & \\
\hline \multicolumn{4}{|l|}{ Covariates } \\
\hline Group $2 \dagger$ & 0.19 & $(-0.22,0.60)$ & .4 \\
\hline Group 3 & 0.07 & $(-0.30,0.45)$ & .7 \\
\hline CPB time* & 0.50 & $(0.13,0.87)$ & .008 \\
\hline Weight & -0.01 & $(-0.02,0.001)$ & .06 \\
\hline Aristotle score $\geq 4$ & 0.60 & $(0.07,1.12)$ & .03 \\
\hline Cardiac failure & 0.52 & $(0.11,0.93)$ & .01 \\
\hline
\end{tabular}

$C I$, Cardiac index; $C P B$, cardiopulmonary bypass. *Log transformation; †placebo and Aristotle $<4$ were reference groups. 
TABLE E4. Multivariate Poisson regression to test whether PRISM score was significantly associated with study group after adjusting for study covariates

\begin{tabular}{lccc}
\hline \multicolumn{1}{c}{ Covariates } & IRR & $\mathbf{9 5 \%}$ CI & $\boldsymbol{P}$ value* \\
\hline Pseudo $R^{2}$ & .043 & & \\
Covariates & & & \\
Group 2 $\dagger$ & 1.37 & $(0.98,1.89)$ & .06 \\
Group 3 & 1.12 & $(0.82,1.52)$ & .5 \\
$\quad$ Asthma & 2.05 & $(1.33,3.17)$ & .001 \\
Aristotle score $\geq 4$ & 1.16 & $(0.80,1.68)$ & .4 \\
CPB time $>60$ min $\ddagger$ & 1.18 & $(1.03,1.36)$ & .015 \\
\hline
\end{tabular}

PRISM, Pediatric Risk of Mortality; $C I$, confidence interval; $C P B$, cardiopulmonary bypass. ${ }^{*} \log$ transformation; $\nmid$ Placebo and Aristotle $<4$ were reference groups. $\ddagger$ CPB time $\leq 60$ minutes was the reference group. 